Journal of

Women's Health and Gynecology

\title{
An Alternative Treatment for the Ovarian Ectopic Pregnancy
}

\author{
Luke Chatburn, Reesha Sanghani
}

Vanderbilt University School of Medicine, Obstetrics and Gynecology, Nashville, TN 37232

${ }^{*}$ Corresponding author: Reesha Sanghani, Obstetrics and Gynecology, Vanderbilt Women's Health, Suite 27100, 719 Thompson Lane, Nashville, TN 37204, Tel: 615-936-1113; Fax: 615-936-1106; Email: Reesha.sanghani@vanderbilt.edu

Received Date: February 20, 2015; Accepted Date: May 06, 2015; Published Date: May 08, 2015

Citation: Luke Chatburn, et al. (2015) An Alternative Treatment for the Ovarian Ectopic Pregnancy. J Womens Health Gyn 1: $1-2$

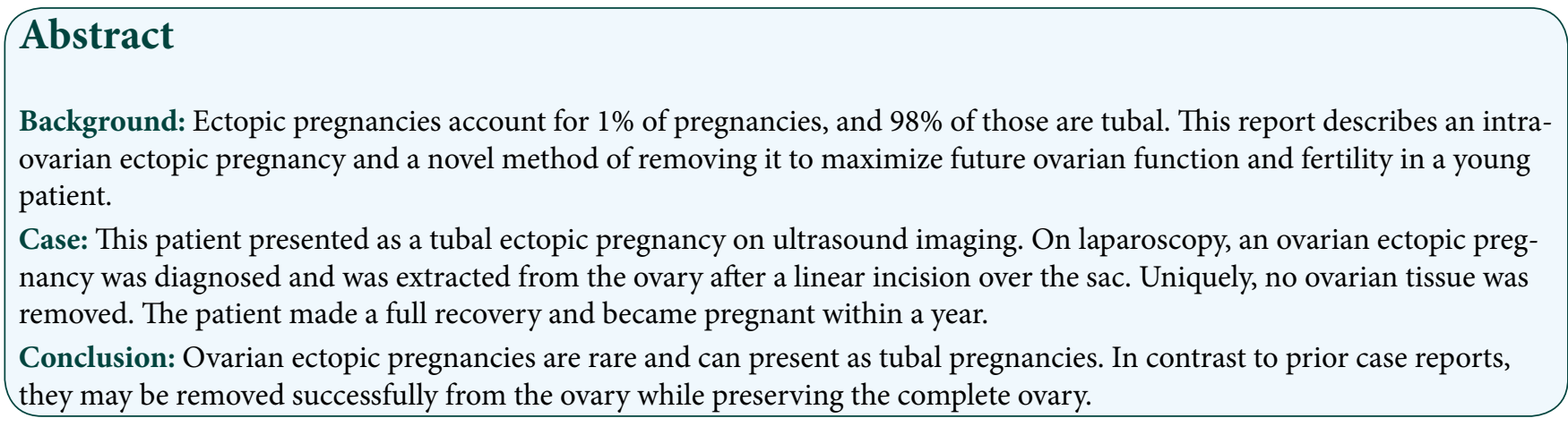

\section{Introduction}

Ectopic pregnancy is familiar to most practitioners, despite its relative rarity. Only $1 \%$ of pregnancies are ectopic in nature, and of those, $98 \%$ are tubal ectopic pregnancies [1]. The remainder of ectopic pregnancies are cornual, cervical, abdominal and ovarian. All of these are rare enough that establishing their proportion is difficult. Because ovarian ectopic pregnancies are some of the rarest of these types, a set of criteria called the Spiegelberg criteria is available to attempt to establish the diagnosis which consists of four criteria. These include: 1) the gestational sac is located in the region of the ovary; 2) the ectopic pregnancy is attached to the uterus by the ovarian ligament; 3) ovarian tissue in the wall of the gestational sac is proved histologically; and 4) the tube on the involved side is intact.

These criteria frequently fail to be satisfied by known cases [2]; thus, the diagnosis is clinical [3] Frequently, ovarian ectopic pregnancy is distinguished from tubal ectopic pregnancy based on location at the time of removal. Attempts have been made to describe ultrasonographic findings to distinguish these entities; but while they are inclusive, they are not exclusive at this time [4] Therefore, due to the rarity of ovarian ectopic pregnancy, the etiology is presumptive, rather than adequately proven

C 2015 The Authors. Published by the JScholar under the terms of the Creative Commons Attribution License http://creativecommons.org/licenses/ by/3.0/, which permits unrestricted use, provided the original author and source are credited.
Given the range of cases reported in the literature [5], both intra- and extra-ovarian, it is apparent that two distinct entities exist - fertilization of the ovum within the follicle (either due to pre-ejection fertilization or failure of ejection), and fertilization immediately after ejection that implants on the ovarian surface or adjacent tissue (such as the tubal externa or uteroovarian ligament). These two etiologies may be distinguished by finding a plane of division between the pregnancy and the ovary.

Given these etiologies, three methods have been previously described to remove ovarian ectopic pregnancies: 1) In the case of extra-ovarian ectopic pregnancy, excision along the dividing plane, 2) For intra-ovarian ectopic, wedge resection $[6,7]$, or [3] oophorectomy.

\section{Case}

This 26-year-old G2P0010 initially presented to an outside hospital emergency department, reporting 1 week of lower abdominal pain starting 4 weeks after her last menstrual period. Ultrasound performed at that time showed an approximately $5 \mathrm{~cm}$ solid cystic mass within the cul-de-sac. Neither ovary was visualized, nor were uterine contents identified. At the time, her $\beta$-hCG was $1064 \mathrm{mIU} / \mathrm{mL}$, and there was no free fluid in the cul-de-sac.

As instructed, the patient followed up in clinic 4 days after that with a $\beta$-hCG value of $8175 \mathrm{mIU} / \mathrm{mL}$, rising appropriately. She continued to have slowly worsening abdominal pain, without 
nausea or vomiting, other signs of infection, or vaginal bleeding. Transvaginal ultrasound was once again performed identifying the cul-de-sac mass similar to previous imagery, and a right adnexal ectopic pregnancy with sac and surrounding vascular ring, implying a classical tubal pregnancy. Moreover, moderate free fluid was visualized within the cul-de-sac, concerning for rupture. Interestingly, the mass and the ectopic pregnancy were identically sized (Figure. 1).

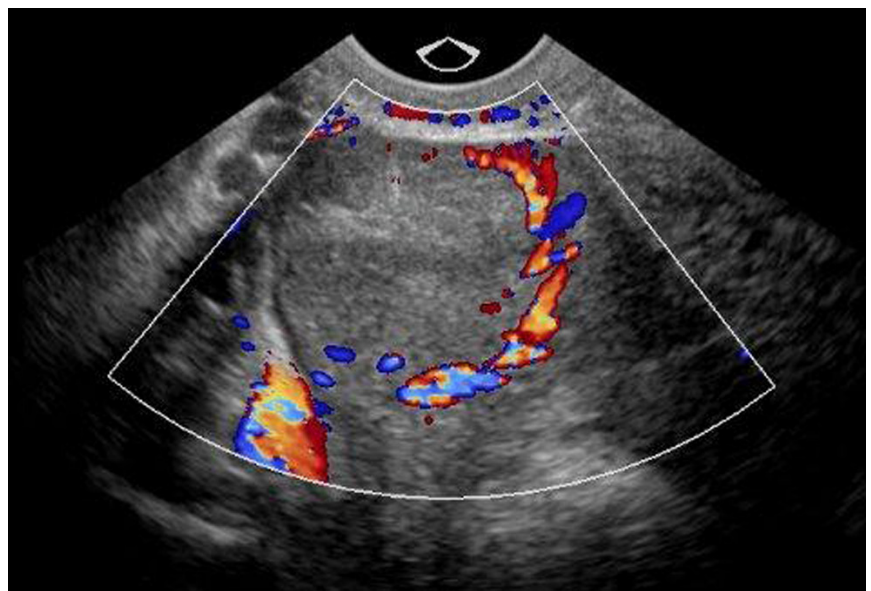

Figure 1: Trans-vaginal image of ectopic pregnancy with classic 'Ring of Fire' sign.

\section{Surgical course}

The patient was transferred to the emergency room and admitted for surgical intervention. Ultrasound images were reviewed with on-site radiologists, who concurred with the reading. The patient was taken to the operative room for planned laparoscopic removal of ectopic pregnancy either by salpingostomy or salpingectomy.

Laparoscopic entry was made and abdominal survey showed no abnormal findings. On visualization of the pelvis, however, the right fallopian tube showed no tubal distension, erythema or other signs of ectopic pregnancy. This tube was entirely inconsistent with appearance of the ectopic pregnancy on ultrasound (Figure. 2). The left tube and ovary were carefully examined and proved to be normal.

At this point, the uterus was elevated in the pelvis and the right ovary was visualized deep within the cul-de-sac. It was abnormally enlarged to half of the diameter of the uterus. The ovary was gently elevated out of the pelvis, and a large string of thick, heterogeneous clot was noted to be extruding from an opening in the medial aspect (Figure 3).

At this time, a diagnosis of ovarian ectopic was highly likely, and options for removal were reviewed (oophorectomy, salpingoophorectomy, wedge resection). The decision was made to proceed with linear oophorostomy in order to preserve the ovary.

The ovary was gently stabilized with atraumatic graspers and elevated to present the existing opening. The clot fell away, and the margins of the opening were clearly visible. Monopolar scissors were used to extend the opening laterally to a length of approximately $2 \mathrm{~cm}$ and products of conception were re-

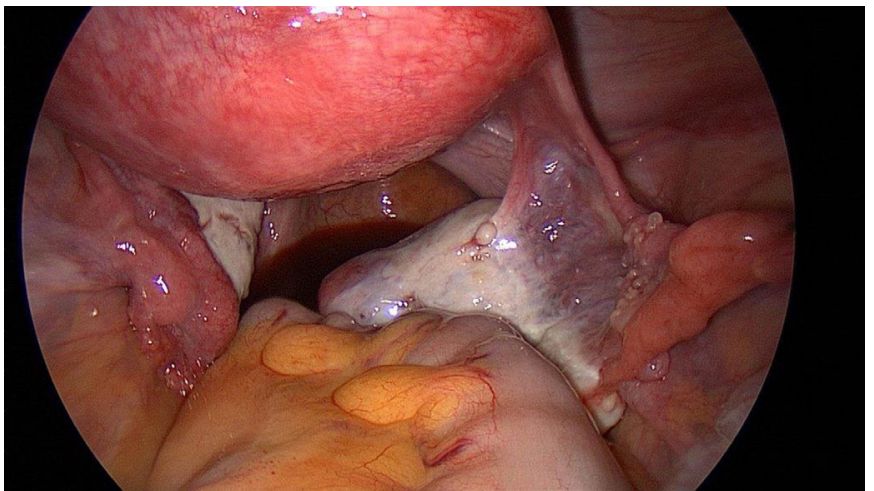

Figure 2: Visualized right fallopian tube, without expected ectopic pregnancy.

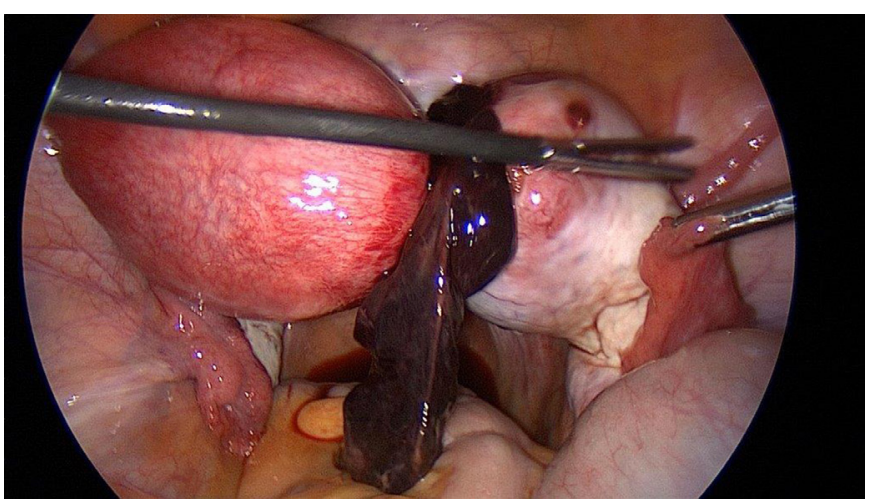

Figure 3: Right ovary with extruded clot.

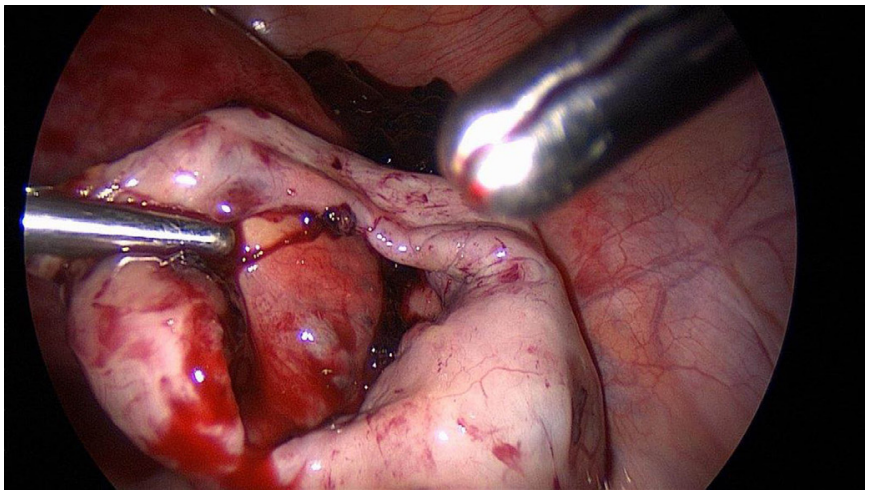

Figure 4: Examination of the inter-ovarian bed after extraction of all tissue.

moved with an endocatch bag. Small areas of bleeding were cauterized and the bed was inspected showing ovarian stroma throughout (Figure. 4).

While ultrasound findings and laparoscopic findings were convincing for ovarian ectopic pregnancy, it is estimated that $15-20 \%$ of ectopic pregnancies are not adequately removed (rarely heterotopic, more commonly misdiagnosis or technique failure), and some continue to develop postoperatively. For this reason, dilation and curettage was performed in order to prove the uterine contents and reinforce the diagnosis postoperatively. Unfortunately, our pathology did not provide products of conception and only found blood clot in our laparoscopic specimen; however, our dilation and curettage results also did not find fetal or villous tissue allowing us to come to the conclusion that it was still an ovarian ectopic based on our other findings. 


\section{Postoperative course}

Postoperatively, the patient experienced no complications. She followed up in clinic 1 week after the procedure, and was healing well. She had no issues with pain control or further signs or symptoms of pregnancy. Serial $\beta$-hCG values were followed, and they rapidly descended to zero (POD\#4 $=509 \mathrm{mIU} / \mathrm{mL}$, POD\# $11=28 \mathrm{mIU} / \mathrm{mL}$, POD\#20=undetectable).

\section{Comment}

In the case of this patient, fertilization clearly occurred within the follicle itself, as the complete structure was surrounded by ovarian epithelial tissue. Unlike the majority of documented ovarian ectopic pregnancies that fall into the class of postejection fertilizations due to a well-defined cleavage plane, this case proves the existence of the pre-ejection type.

Beyond the question of initial location, this case also provides a unique case of intra-ovarian ectopic pregnancy caught in the process of active abortion. While it stands to reason that ovarian ectopic pregnancies should have a similar spontaneous rate to tubal ectopic ( $50 \%)$, we found none documented, let alone photographed.

Finally, this case does represent the proof of concept that an ovarian ectopic pregnancy may be managed with removal of the pregnancy itself without ovarian injury, and that incision and extraction is an appropriate method for doing so.

\section{Teaching points}

Since ovarian ectopic pregnancies are rare, the best treatment for these pregnancies has not been clearly identified. Therefore, it is important to remember to consider salvaging the complete ovary, if possible, especially in patients who desire future fertility.

\section{References}

1) Scutiero G, Di Gioia P, Spada A, Greco P (2012) Primary ovarian pregnancy and its management. JSLS 16: 492-494.

2) Sergent F, Mauger-Tinlot F, Gravier A, Verspyck E, Marpeau L (2002) [Ovarian pregnancies: revaluation of diagnostic criteria]. J Gynecol Obstet Biol Reprod (Paris) 31: 741-746.

3) Crochet JR, Bastian LA, Chireau MV (2013) Does this woman have an ectopic pregnancy?: the rational clinical examination systematic review. 309: 1722-1729.

4) Comstock C, Huston K, Lee W (2005) The ultrasonographic appearance of ovarian ectopic pregnancies.105: 42-45.

5) Joseph RJ, Irvine LM (2012) Ovarian ectopic pregnancy: aetiology, diagnosis, and challenges in surgical management. 32: 472-474.

6) Tinelli A, Hudelist G, Malvasi A, Tinelli R (2008) Laparoscopic management of ovarian pregnancy.12: 169-172.

7) Odejinmi F, Rizzuto MI, Macrae R, Olowu O, Hussain M (2009) Diagnosis and laparoscopic management of 12 consecutive cases of ovarian pregnancy and review of literature. J Minim Invasive Gynecol 16: 354-359.
Submit your manuscript to a JScholar journal and benefit from:

ฯ Convenient online submission

๑ Rigorous peer review

I Immediate publication on acceptance

ฯ Open access: articles freely available online

I High visibility within the field

- Better discount for your subsequent articles

Submit your manuscript at http://www.jscholaronline.org/submit-manuscript.php 